\section{Eosinophilic granulomatosis with polyangiitis involving the small intestine: radiographic and endoscopic findings}
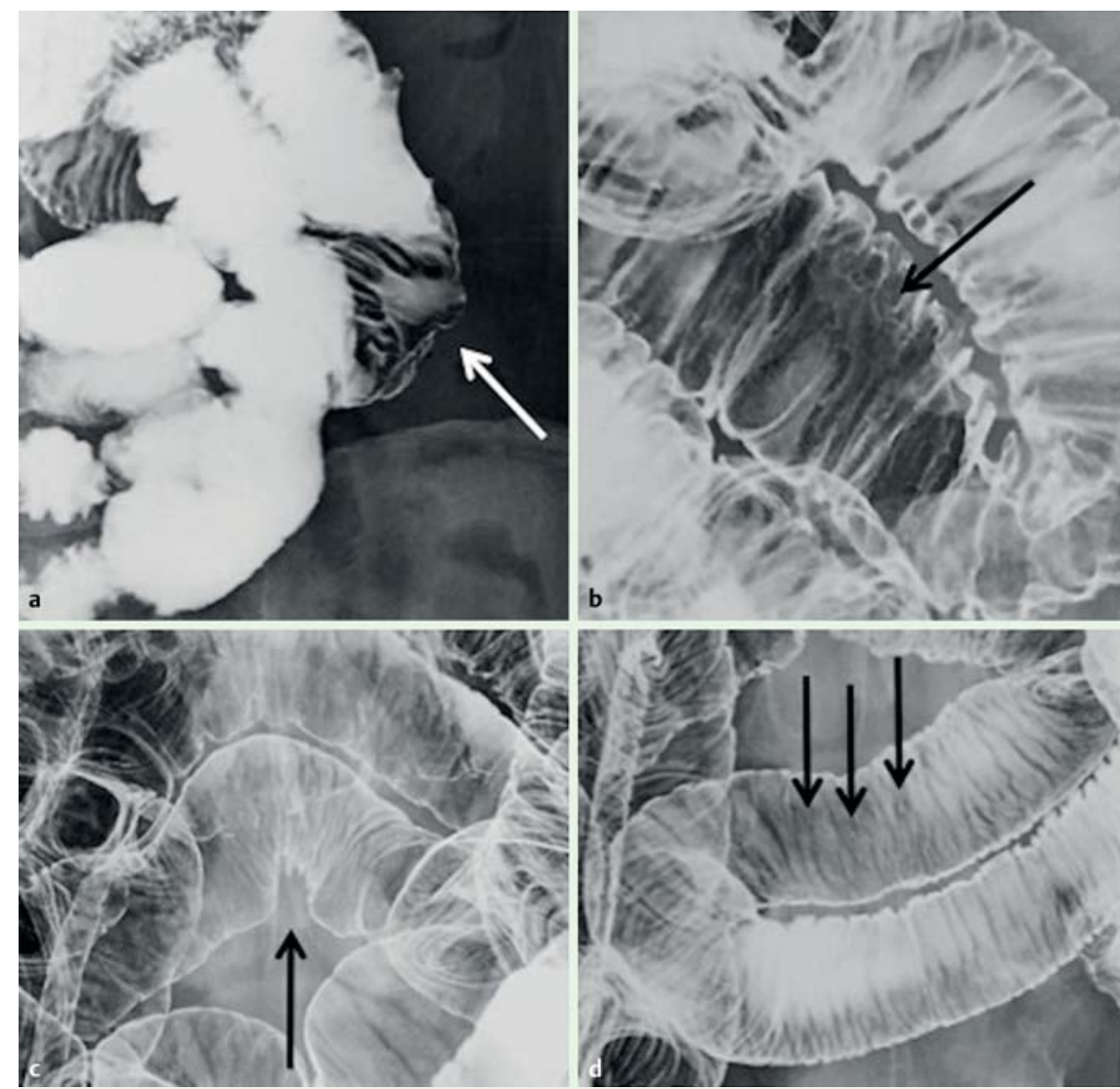

Fig. 1 Double-contrast radiographic images of the small bowel in a 55-year-old man who has an established diagnosis of eosinophilic granulomatosis with polyangiitis. a, b Multiple irregular ulcers in the jejunum (arrows). c An eccentric change in the ileum (arrow). $\mathbf{d}$ Multiple erosions in the ileum (arrows).

Eosinophilic granulomatosis with polyangiitis (EGPA), previously referred to as Churg-Strauss syndrome, is an eosinophilic vasculitis that involves the lungs, peripheral nerves, and gastrointestinal (GI) tract [1].

A 55-year-old man who had an established diagnosis of EGPA with asthma, marked eosinophilia, and fever visited our institution because of epigastralgia. Esophagogastroduodenoscopy (EGD) re- vealed erosions in the antrum and duodenum. Biopsy specimens obtained from the erosions showed eosinophilic infiltration in the muscularis mucosae and submucosa. Abdominal computed tomographic scans obtained immediately after the start of intravenous prednisolone depicted thickening in the wall of the small bowel; therefore, we performed small-bowel radiography, which showed multiple irregular ulcers and erosions in the jejunum and ileum ( $\bullet$ Fig.1). Capsule endoscopy ( $\bullet$ Fig.2), as well as antegrade and retrograde double-balloon endoscopy (DBE) (৫ Fig.3), showed multiple sharply demarcated ulcers in the jejunum and ileum. After the oral administration of prednisolone for 3 months, capsule endoscopy revealed that the ulcers had healed (৫ Fig.4).

The GI tract is involved in approximately $20 \%$ to $50 \%$ of patients with EGPA [1], and it has been suggested that small-bowel involvement in EGPA is a sign of a poor prognosis [2]. However, the radiographic and endoscopic findings of small-intestinal lesions in EGPA are still unclear, probably because most of the small-bowel lesions previously discussed have been in patients with GI tract perforation [3]. To date, only two cases of small-bowel lesions examined by capsule endoscopy or DBE have been reported [4,5]. In those patients, multiple punched-out ulcers were found in the small intestine. In our patient, small-bowel radiography, in addition to capsule endoscopy and DBE, depicted irregular ulcers and small erosions. Our case suggests that small-bowel radiography and capsule endoscopy are convenient procedures for the diagnosis of small-bowel lesions in EGPA and the evaluation of their clinical course.

\section{Endoscopy_UCTN_Code_CCL_1AC_2AD}

\section{Competing interests: None}

\section{Keisuke Kawasaki ${ }^{1}$, Makoto Eizuka², Okinori Murata ${ }^{3}$, Kazuyuki Ishida², Shotaro Nakamura', Tamotsu Sugai ${ }^{2}$, Takayuki Matsumoto ${ }^{1}$}

${ }^{1}$ Division of Gastroenterology, Department of Internal Medicine, Iwate Medical University, Morioka, Japan

2 Department of Diagnostic Pathology, Iwate Medical University, Morioka, Japan ${ }^{3}$ Division of Pulmonary Medicine, Allergy, and Rheumatology, Department of Internal Medicine, Iwate Medical University, Morioka, Japan 

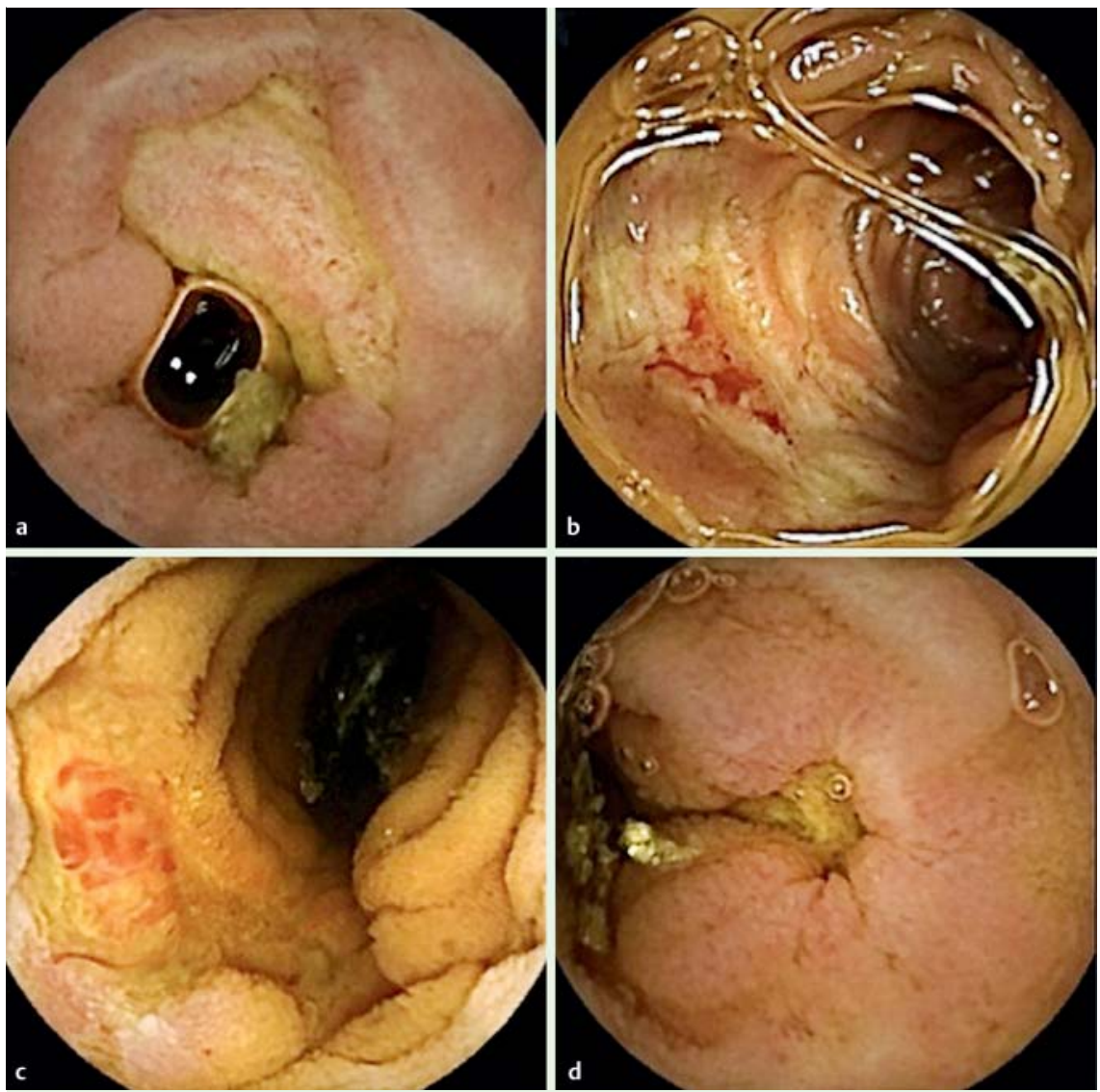

Fig. 2 Capsule endoscopy images of multiple sharply demarcated ulcers: a, b in the jejunum; c, $\mathbf{d}$ in the ileum.
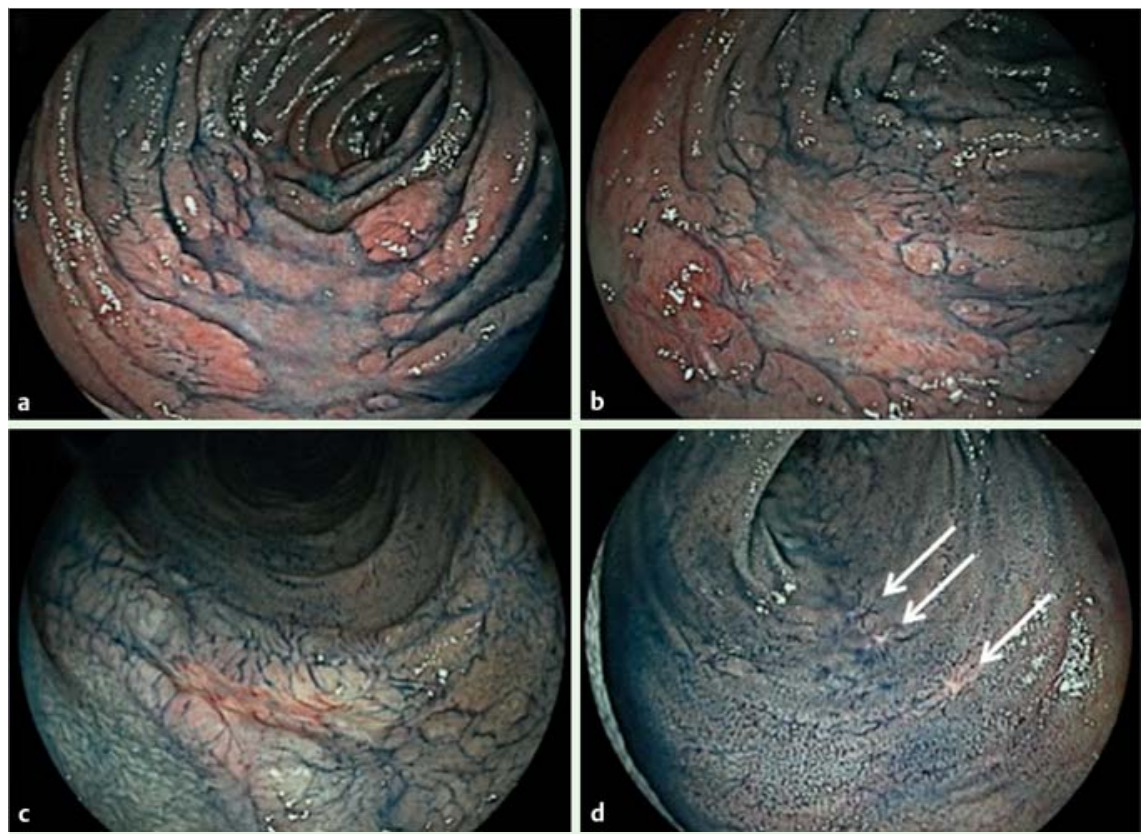

Fig. 3 a, b Antegrade double-balloon endoscopy (DBE) with the use of indigo carmine reveals multiple irregular ulcers with thickened folds and erythematous mucosa in the jejunum. c, $\mathbf{d}$ Retrograde DBE with indigo carmine shows a sharply demarcated ulcer (c) and multiple erosions (arrows, $\mathbf{d}$ ) in the ileum.

\section{References}

1 Chumbley LC, Harrison EG Jr, DeRemee RA. Allergic granulomatosis and angiitis (Churg-Strauss syndrome). Report and analysis of 30 cases. Mayo Clin Proc 1977; 52: 477-484

2 Guillevin L, Cohen P, Gayraud M et al. ChurgStrauss syndrome. Clinical study and longterm follow-up of 96 patients. Medicine 1999; 78: 26-37

3 Assmann $G$, Molinger $M$, Pfreundschuh $M$ et al. Gastrointestinal perforation due to vasculitis at primary diagnosis of eosinophilic granulomatosis with polyangiitis (EGPA) despite a high dose glucocorticosteroids treatment. Springerplus 2014; 3: 404

4 Sánchez R, Aparicio JR, Baeza T et al. Capsule endoscopy diagnosis of intestinal involvement in a patient with Churg-Strauss syndrome. Gastrointest Endosc 2006; 63: $1082-1084$

5 Suzuki T, Matsushima M, Arase Y et al. Double-balloon endoscopy-diagnosed multiple small intestinal ulcers in a Churg-Strauss syndrome patient. World J Gastrointest Endosc 2012; 4: 194-196 

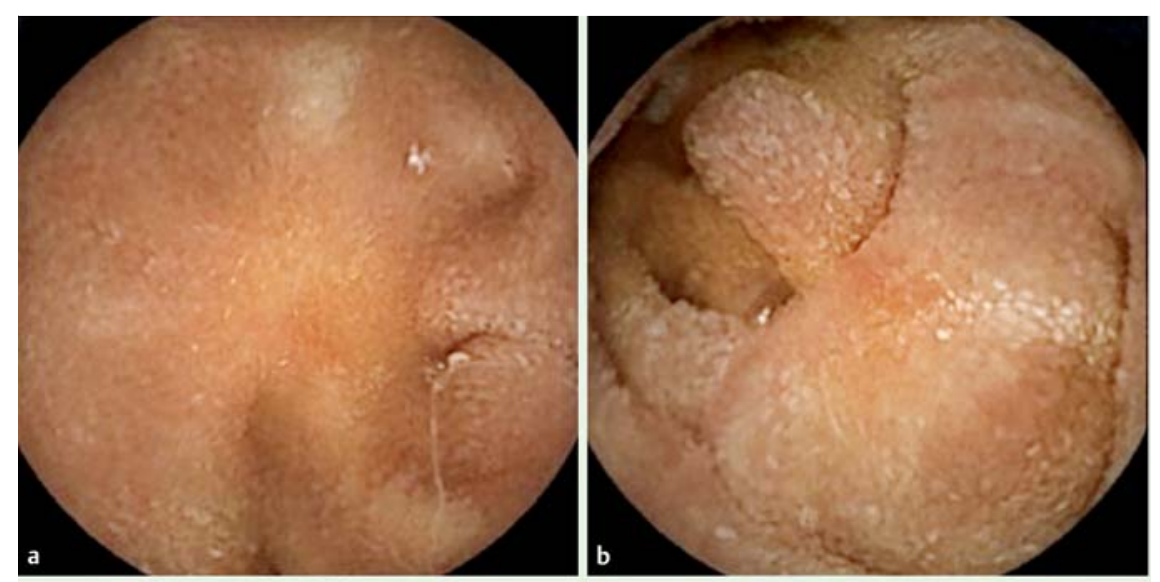

\section{Bibliography}

Dol http://dx.doi.org/

10.1055/s-0034-1393140

Endoscopy 2015; 47: E492-E494

(c) Georg Thieme Verlag KG

Stuttgart · New York

ISSN 0013-726X

\section{Corresponding author \\ Keisuke Kawasaki, MD}

Division of Gastroenterology

Department of Internal Medicine

Iwate Medical University

Uchimaru 19-1

Morioka 020-8505

Japan
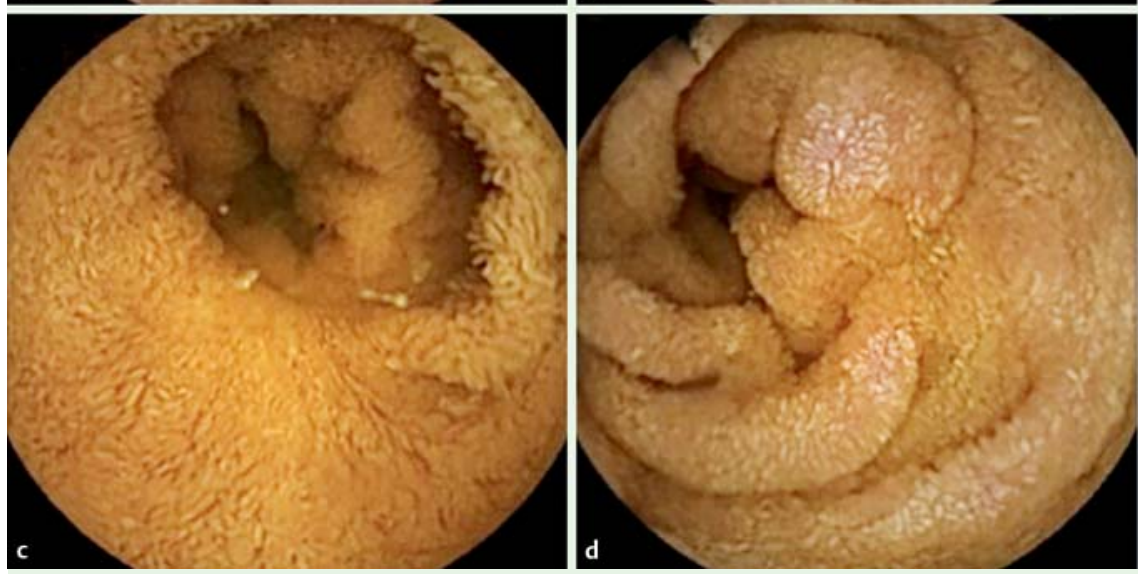

Fax: +81-19-652-6664

kkeisuke@iwate-med.ac.jp

Fig. 4 Capsule endoscopy images obtained after 3 months reveal that multiple ulcers have healed: $\mathbf{a}, \mathbf{b}$ in the jejunum; $\mathbf{c}, \mathbf{d}$ in the ileum. 